\title{
Translation ethics wikified: How far do professional codes of ethics and practice apply to non-professionally produced translation?
}

\author{
Joanna Drugan \\ University of Leeds
}

Translation involves ethical decision-making in challenging contexts. Codes of practice help professional translators identify ethical issues and formulate appropriate, justifiable responses. However, new and growing forms of community translation operate outside the professional realm, and substantial differences exist between the two approaches. How relevant, then, are professional codes in the new contexts? What alternative 'codes' (stated or implicit) have been developed by the new groups? The content of professional codes is compared here to a broad range of community approaches to identify themes common across both, and areas where the new community might be making an original contribution. This reveals different priorities in the professional and non-professional codes. Community translation initiatives have found novel solutions to some ethical problems and challenges, particularly in self-regulation and community policing, improved interpretation of code content, an emphasis on shared values rather than individual rights, and strong mentoring.

\section{Codes in translation: confrontation, innovation}

Professional codes of ethics have a long history, dating back to at least the $18^{\text {th }}-19^{\text {th }}$ centuries in the fields of law and medicine (Davis, 2003). In the late $20^{\text {th }}$ century, as translation became professionalised or 'industrialised' in Gouadec's image (2009, p. 217), dozens of codes specific to translation and interpreting were developed in countries where these activities were practised by large numbers of linguists. Most professional translation associations with an online presence today post some version of a code of professional conduct or ethics. ${ }^{1}$ Translation followed the classic pattern of the development of a profession leading on to its public codification (Brooks, 1989). Unsurprisingly, ethical codes were collectively identified as necessary: issues raised by translation are often 'profoundly ethical, and not merely technical' (Goodwin, 2010, p. 20). (Consider, for example, such daily ethical decisions as whether to accept work for clients in sensitive medical domains like abortion; or how extreme situations of conflict and war affect the translator's role.) Codes of ethics and conduct have been 
developed precisely to support professionals in considering such issues and to equip them to formulate appropriate and justifiable responses.

However, emerging forms of 'community' translation ${ }^{2}$ - pro bono, political/activist, crowdsourced, fan translation, free/Open Source software (FOSS) localisation-operate outside this professional framework. Substantial differences exist between the two models: non-professional translations are usually not commissioned or assigned, but voluntary; unpaid or remunerated well below professional rates; lightly or unregulated; subject to no contractual agreement or contracted on imposed terms with no negotiation; public, not confidential; continually evolving and editable, rather than finalised and protected. The translations are often collaborative and performed by self-selecting individuals from diverse backgrounds, whether in terms of training, experience, subject knowledge, competence or membership of professional associations. Community translation is thus not bound, or even directly addressed, by the existing professional codes.

Yet there is clearly a need for translators in non-professional contexts to be able to draw on such ethical support. One of the pioneers in crowdsourced translation, Wikipedia, found it such a bruising experience that those involved concluded 'Wikipedia is 10\% translation and $90 \%$ confrontation' (http://meta.wikimedia.org/wiki/Meta:Babel). Most community translation initiatives exist online, and the potentially negative impact of this environment on aspects of ethical conduct has now been widely observed; see, for example, Bannerjee et al. (1998), Loch and Conger (1996), and Warner and Raiter (2005). As Floridi (1999) summarises:

Because of the remoteness of the process, the immaterial nature of information and the virtual interaction with faceless individuals, the information environment (the infosphere) is easily conceived of as a magical, political, social, financial dream-like environment, and anything but a real world, so a person may wrongly infer that her actions are as unreal and insignificant as the killing of enemies in a virtual game. (p. 40)

The present article takes the leading professional codes as its starting point: how far are these appropriate or helpful in the new, challenging nonprofessional contexts? To illustrate the differences between the two models, themes common across the leading professional codes are identified, then a case study of one non-professional translation approach is outlined and mined for insights into how ethical issues are handled in the new community translation contexts. It is argued that the new translation communities are developing their own distinct, often tacit or implicit, 'codes' of ethics and practice. 
Désilets (2007) first pointed to the emerging 'wikification' of translation, suggesting that the new model might have much to offer for established approaches to translation.

Massive online collaboration might change the rules of the game for translation, by sometimes introducing new problems, sometimes enabling new and better solutions to existing problems, and sometimes introducing exciting new opportunities that simply were not on our minds before. $(2007$, n.p.)

Some such potential changes, solutions and opportunities lie in the important area of ethical behaviour. Certain community endeavours are breaking new ground in ethical translation activity - cf. initiatives such as high-speed MT and SMS/GPS addressing the translation needs of Haitians after the earthquake (Lewis, 2010; Munro, 2010). Professional translation might thus also be able to profit from the wisdom of non-professionals: the conclusion of this article summarises potential lessons from the new model and further questions raised by it. Among an increasingly vocal chorus making bleak predictions for today's professional 'class' of translators (e.g., Gouadec, 2009), Garcia foresees 'an approaching future in which translation may once again be the realm of the gifted amateur or keen bilingual subject specialist', with professional translators working in 'lowpaid, call-centre conditions' $(2009$, p. 199, p. 211). A final reason that these non-professional approaches to ethics matter, then, is that the context in which they were developed may one day prevail. Enlightened self-interest should lead professional translators to consider them carefully.

\section{Methodology: Selection of ethical codes and community equivalents}

There are many studies of ethical codes in one individual field (e.g., for accounting, information science or medicine), but thus far only one published study of codes particular to the translation profession (McDonough Dolmaya, 2011). There is no prior study comparing translation-specific codes with those of other professions, or with equivalents in non-professional contexts.

McDonough Dolmaya (2011) examined seventeen translationspecific ethical codes from fifteen countries, identifying common principles; she then compared these to professional translators' ethical concerns in online forums to identify gaps in the guidelines. The present study includes ten of the codes considered by McDonough Dolmaya and fourteen additional translation-specific codes, covering nineteen countries and three international organisations; all of these are available online in English or French, the languages available to the author (see Appendix 1). The selected codes were analysed (or re-analysed, in the case of those considered by McDonough Dolmaya) in order to categorise the ethical 
issues and principles they addressed - and those they did not. These broad categories for translation ethics were then compared to those identified in professional codes from other disciplines in the few cross-discipline studies available and in several discipline-specific studies from other fields.

For non-professional translation contexts, an online sample was again gathered, including some of the longest-running and largest community translation initiatives and again targeting those available in either English or French. See Appendix 2 for a list of the sixteen accessible sources analysed here; the corpus analysed for the present study also included four non-public 'codes' or agreements, provided to the author by community translation providers or organisations. ${ }^{3}$ Two differences with the professional context were immediately apparent. First, community translation is more diverse and sometimes operates outside the law, e.g. bootleg fan translations. Second, non-professional ethical 'codes' were often not presented as such. Recognisable 'code-like' content was identified in files described as community guidelines, terms of service, user agreements, founding principles, charters, guiding principles, site rules, terms and conditions, cornerstones, manifestos, bylaws, policies and protocols. 'Code-type' content was also presented inside other material, e.g., FAQs and user-generated bulletin boards/chat rooms/threads dedicated to issues of ethics or conduct.

The two sets of translation 'code' content are compared in the next section, and a table presents these alongside typical code content from other professions. Following this, in Section 4, a brief discussion of a community translation case study focuses on how some gaps in the professional codes might be being addressed by emerging practice.

\section{Comparing professional and non-professional codes}

Comparative studies of codes of ethics across two or more different professions are scarce but point to a 'common base' for such codes, ${ }^{4}$ in that they all 'address the problem of moral hazard, provide the norms of professional courtesy, and define the public interest' (Higgs-Kleyn \& Kapelianis, 1999, 367). Codes in such analyses are often categorised by approach, as in Frankel's three types: 'aspirational' (those which focus on setting out ideals), 'educational' (those which provide commentary, improving understanding of issues) and 'regulatory' (those which lay down rules to govern professional conduct and adjudicate in cases of grievances); a code can contain elements of more than one type (1989, p. 109).Beyond this broad-brush common base, more specific shared concerns are found in the professional translation codes, as would be expected. Künzli's examination of ethical aspects of translation revision draws out 'commitment to the highest standards of performance, willingness to 
improve one's skills and knowledge, adaptability, discretion, professional appearance and loyalty' (2007, p. 24), for instance.

Table 1 allows comparison of translation-specific professional codes with the non-professional translation approaches sampled here and with those of some other professions. In the first column, it lists the ten most common principles or themes identified in translation-specific professional codes, in descending order, based on their frequency across the corpus considered for the present article. Next, the ten most common concerns in the community translation context, based on the sample considered here, are listed in descending order, based on their frequency across the corpus considered for the present article. Finally, in the third column, themes in other professions' codes are taken from the few comparative crossprofession studies available, including Brooks (1989), Davis (2003), Frankel (1989) and Koehler and Pemberton (2000); obvious caveats are that the lists for these cross-profession studies are now dated and generally restricted to North America. These themes are listed in alphabetical order rather than in order of frequency, as data were not always sufficiently precise or directly comparable, given the range of sources from which they were drawn. This table is not comprehensive, given the obvious problems of access to representative contemporary data for all professions. Nonetheless, the pattern of the main themes important in each context can be identified through this approach. 
Table 1: Comparison of professional translation codes with non-translation and community translation 'codes'

\begin{tabular}{|c|c|c|}
\hline Professional Translation & Community Translation & Other Professions \\
\hline Competence & $\begin{array}{l}\text { General statement of } \\
\text { philosophy (values, } \\
\text { vision) }\end{array}$ & Competence \\
\hline $\begin{array}{l}\text { Confidentiality, } \\
\text { trustworthiness } \\
\end{array}$ & $\begin{array}{l}=2 \text { Conduct of } \\
\text { contributors }\end{array}$ & Conduct of personnel \\
\hline $\begin{array}{l}\text { Solidarity with other } \\
\text { translators, professional } \\
\text { loyalty }\end{array}$ & $=2$ Legal responsibilities & $\begin{array}{l}\text { Confidentiality, } \\
\text { trustworthiness }\end{array}$ \\
\hline $\begin{array}{l}=4 \text { General statement of } \\
\text { philosophy }\end{array}$ & $\begin{array}{l}=4 \text { 'Client' right to block } \\
\text { participation }\end{array}$ & $\begin{array}{l}\text { Conflict of interest; } \\
\text { impartiality }\end{array}$ \\
\hline $\begin{array}{l}=4 \text { Conflict of interest, } \\
\text { impartiality }\end{array}$ & $\begin{array}{l}=4 \text { Prohibitions (cheating, } \\
\text { porn, spamming, trolling } \\
\text { etc) }\end{array}$ & $\begin{array}{l}\text { Customer needs and } \\
\text { relations }\end{array}$ \\
\hline Client needs and relations & $=6$ Competence & $\begin{array}{l}\text { General statement of } \\
\text { philosophy }\end{array}$ \\
\hline$=7$ Quality of work & $\begin{array}{l}=6 \text { Impersonation (use } \\
\text { real identity, verifiable } \\
\text { email address, confirm } \\
\text { age) }\end{array}$ & Legal responsibilities \\
\hline $\begin{array}{l}=7 \text { Conduct of personnel, } \\
\text { general behaviour }\end{array}$ & $\begin{array}{l}\text { Confidentiality, } \\
\text { trustworthiness }\end{array}$ & $\begin{array}{l}\text { Product or service-related } \\
\text { commentary }\end{array}$ \\
\hline$=9$ Legal responsibilities & $\begin{array}{l}=9 \text { Duty to report } \\
\text { violations of code }\end{array}$ & $\begin{array}{l}\text { Shareholders, } \\
\text { stakeholders }\end{array}$ \\
\hline $\begin{array}{l}=9 \text { Commitment to } \\
\text { ongoing professional } \\
\text { development }\end{array}$ & $\begin{array}{l}=9 \text { Ownership of } \\
\text { translations }\end{array}$ & Social issues \\
\hline
\end{tabular}

Examining the themes in codes comparatively serves to highlight both similarities and some revealing differences between professional and nonprofessional approaches, which will now be summarised. First, there are evident conflicts, contradictions and gaps. Such problems are not unique to translation codes: they have previously been noted for other professional contexts (e.g., Savan, 1989). For instance, provisions around confidentiality are placed high in the concerns of most professional codes, but they also stress the duty of translators to report any suspected illegal activities or illicit content to the authorities (Wagner, 2005). How is the individual translator to resolve these conflicting duties with confidence? Künzli (2007) outlines a range of similar conflicts relating to loyalty and duties as outlined 
in professional codes: is the translator's primary allegiance then to the client, ST author, profession, or himself? Higgs-Kleyn and Kapelianis (1999) suggest that loyalty to the client usually trumps the other interests, as he is paying for the work; but as Künzli stresses, such issues can hardly be solved satisfactorily by individuals. There is a role here for translators' associations to address such dilemmas as the conflict between professional demands for speed and low cost, and the ethical commitment to 'thoroughness, reliability or quality' (2007, p. 53).

As well as conflicts within individual codes, there are contradictions and conflicts across different professional codes. This is important when we consider that translators are often bound by multiple codes simultaneously. For instance, a UK translator might well be a member of the Institute of Translation and Interpreting (ITI) and Chartered Institute of Linguists (CIoL), while carrying out work for a company which subscribes to the Association of Translation Companies (ATC) code and has also signed up to the Unesco Translator's Charter. Which code should have priority where there are conflicting provisions across a range of codes? Brooks sees a role for an ethical "ombudsman" in such scenarios (1989).

A final way in which professional codes fail translators is that there are gaps in their provisions, notably in interpreting the codes. If key terms such as accuracy are not defined clearly, translators 'may actually be endorsing slightly different values' without realising it (McDonough Dolmaya, 2011, p. 34). Similarly, gaps in enforcing ethical provisions are often raised in criticisms of professional codes. Professionals in different fields typically believe that 'their peers contravene their professional codes relatively often' (Higgs-Kleyn \& Kapelianis, 1999, p. 363), yet there are few mechanisms to monitor non-compliance or reward the bravery of whistle-blowers (Higgs-Kleyn \& Kapelianis, 1999, p. 365).

Despite their limitations, professionals surveyed for studies of other disciplines' codes overwhelmingly viewed their codes as necessary: an average of $81.8 \%$ saw them as 'very necessary' in one study of three professions (Higgs-Kleyn \& Kapelianis, 1999, p. 369). If, despite their flaws, professionals view them so positively, they are clearly addressing a real need, at least in part. How then do community approaches address this need? Might their emerging strategies complement or complete existing professional codes?

As Table 1 makes clear, the non-professional codes (and equivalent documents) reveal different priorities. Most non-professional approaches emphasise two strategies in tandem. First, they typically place shared values and an explicit community vision much higher on the agenda than professional codes do. Over three-quarters of the codes from nonprofessional communities begin with a clear and often passionately expressed outline of the community's shared goals, frequently running into several hundreds of words, whereas this is very rare and significantly shorter where it is found in professional codes. The second common feature which can be observed far more strongly in the non-professional codes 
might seem initially contradictory. Whereas professional codes barely mention sanctions if members fail to respect their provisions, the nonprofessional equivalents almost invariably list very detailed potential infractions (from posting images of other users without their consent, to lying about one's age or stalking others) and the potential consequences. The most important issues in professional contexts, including confidentiality and competence, are still recognised, but much lower down the list of priorities; they are entirely absent from quite a few nonprofessional codes.

Instead, we see a new emphasis on community policing in the nonprofessional contexts. The professional codes rarely suggest members have a duty to monitor one another, but community codes make this explicit and frame it positively. There was another noticeable difference in emphasis here, with professional codes stressing members' duty of loyalty to one another, while the new communities seemed to have a different implicit concept of what being community-minded might mean. Loyalty here is to the community as a whole, rather than to potentially challenging individual confrères.

Interestingly, this different emphasis in the new codes addresses criticisms made by ethicists of many professional codes. The crucial importance of 'organizational culture' or 'climate' in fostering ethical behaviour has been repeatedly stressed as a significant gap in existing codes (Higgs-Kleyn \& Kapelianis, 1999, p. 366). In summary, the standard nonprofessional approach (insofar as there is one) would be to emphasise the positive first (stress shared values, play to altruism), then make sure basic ground rules and monitoring are robustly in place to prevent the seemingly inevitable abuse.

A case study of a leading community translation approach can now help draw out how these strategies work in practice.

\section{Case study: FOSS localisation}

One of the most successful community translation endeavours has been the localisation of Free and Open Source Software (FOSS). Volunteers have collaborated online both to develop and localise software into a large number of the world's languages, particularly targeting those spoken by millions in developing countries with little access to standard ICT. FOSS is often presented by those involved in its development and use as ethical per se - challenging the monopolies of software developers, bridging the digital divide and bringing the communications revolution to millions who would otherwise be left behind. As Stallman summarises, "The term free software refers to the social and ethical importance of freedom, as well as to the practical benefits it brings" (Souphavanh \& Karoonboonyanan, 2005, p. 7). It might be tempting to assume that the FOSS localisation community's 
shared goals and high ideals would lead naturally and unproblematically to shared ethical standards; but this assumption is disproved compellingly by this case study.

It is quickly apparent when reading FOSS user codes or home pages that abusive behaviour dogs the initiatives. The second point in the Sun Open Community Translation Interface Terms of Use relates to prohibitions including,

unlawful, threatening, libelous, defamatory, obscene, pornographic, or profane material, any software virus, worm, or other material of a disruptive or destructive nature. [... Users] are further prohibited from using this Website to: (a) transmit spam, bulk or unsolicited communications; (b) pretend to be Sun or someone else, or spoof Sun's or someone else's identity; [...] (e) disrupt the normal flow of dialogue or otherwise act in a manner that negatively affects Users' ability to use this Website. (n.p.)

All FOSS initiatives seem to face issues of spamming, trolling (deliberately posting inflammatory messages), angry reactions, impersonation, intentional harassment of other users and other disruptive behaviour - it is instructive to note how many new terms have been coined just for abusive behaviour in specific web contexts. Marshall (1999) has attributed this in part to Ogburn's "cultural lag" theory - that there is an inherent conflict between the rapid speed of modern technological advances and the slower speed by which ethical guidelines for their utilization are developed. Yet despite the barrage of unethical conduct (or perhaps, rather, precisely because they had to react to it), FOSS localisation initiatives have found novel solutions to ethical problems in non-professional translation.

In FOSS contexts, volunteers are involved in translation with no screening as to their competence or commitment. We might expect that any ethical commitment to professionalism, as stressed in professional translation codes, would be impossible. As Table 1 summarises, professional codes emphasise the need to address such issues as respecting deadlines, and only taking on work for which you are qualified and which you have the necessary resources to complete effectively. In FOSS contexts, these expectations are impossible. Instead of placing the onus on translators to ensure they are competent and ready to meet targets, systems are in place to support the volunteers so such issues are less problematic. Volunteers share the workload across large teams, with effective support through mentoring, specific discussion threads on technical (and other) themes, meaning that any potential lack of comprehension of the ST, for instance, is easily addressed by other motivated volunteers. Large online terminology databases with clear definitions have been drawn up by volunteers and amplified or amended as localisation took place. In contradiction of the professional aversion to admitting ignorance or "bothering" the client with queries, FOSS volunteers are actively 
encouraged to question ST sense and previous translators' (and developers') work. There are often "Report" features or voting mechanisms to signal issues with other participants' work.

Self-regulation by the community seems to work quite successfully on issues beyond professionalism too (banning nuisance members, reactions to trolling, the community coming together to shame abusers or denounce 'unnecessary complaining'), unlike many professionals who have a 'poor track record in this regard' (Frankel, 1989, p. 113), partly because there are 'too few rewards and too many risks' (Frankel, 1989, p. 114). It is difficult to see what rewards there might be in FOSS contexts either, and there are presumably risks there too (for instance, if you respond to the trolls, you are likely to be attacked more vehemently). Perhaps the community's strong commitment to a shared endeavour with noble aims, and knowledge that there will be support from peers, is the key to participants' willingness to react.

Among others, Frankel also recommends the institution of positive mechanisms to encourage "those who exhibit exemplary ethical behaviour" (Frankel, 1989, p.114) and this is a common feature in online community translation and FOSS, with features such as 'badges', kudos points and the possibility to become a (volunteer) 'leader' or mentor for others. An encouraging community atmosphere is also important to keep contributors coming back, normally through support and strong, inspiring leadership: the "Benevolent Dictatorship Principle" (Howe, 2008, p. 284). As the man who claims to have coined the term crowdsourcing stresses, 'communities need community leaders' (Howe, 2008, p. 285).

\section{Conclusion: Solutions and further questions}

Do the non-professional codes and case study offer any lessons for translation professionals and their codes? One encouraging example lies in the issue of interpretation of professional codes. As noted, a common criticism of professional codes in the past has been that there is a need for shared interpretation of the underlying meaning of key provisions. For Frankel (1989),

The profession must institutionalize a process whereby its moral commitments are regularly discussed and assessed in the light of changing conditions both inside and outside the profession. The widespread participation of members in such an effort helps to reinvigorate and bring into sharp focus the underlying values and moral commitments of their profession. (p. 112)

To achieve this kind of ongoing reflection, Brooks has argued that professionals can find that 'discussion groups or case studies are helpful in fleshing out the meaning of their code' (1989, p. 124). Non-professional 
translation communities have benefited from having such discussions live, archiving their interactions and shared conclusions online; and recently, leading professional bodies seem to be following their example. The ATA now states in its Code of Ethics that it is preparing a "commentary" to the Code, "providing in-depth explanation and examples that reflect our common experiences [...] to enable a deeper understanding of the effects of our behavior on ourselves, each other, and the industry as a whole"' (n.p.).

Another potentially rich area which professional associations might explore is the strong non-professional emphasis on shared values and ideals, rather than the individual rights which codes have tended to stress. It could be argued that professional codes' privileging of translators' rights has been fairly pointless. The Unesco Translator's Charter (1963/1994), for instance, lists a covetable range of 'rights' including that of the translator to own the copyright to all his translations (Section II, 15) or to have his name 'mentioned clearly and unambiguously whenever his/her translation is used' (Section II, 17a), yet almost fifty years after its adoption, those rights are even less widespread than in 1963. The non-professional stress on clearly defined values offers an alternative model, one already noted by Künzli as a positive (2007). In other professions, Frankel (1989, p. 112) emphasises the benefits of highlighting 'dominant values' (e.g., improving health care for medics). Some such dominant values for translation might be enabling communication or spreading knowledge; these might inspire members more than desirable, but almost certainly unattainable, 'rights'.

The new communities' shared ethos and continual fostering of emerging leaders are final aspects from which professionals might learn. There are already a few mentoring schemes in professional translation. That these are hugely popular and always oversubscribed demonstrates the hunger for such support from new members of the profession. Embedding mentoring and support schemes in professional development, and seeing this as a normal feature of career progression, could be done relatively easily using the online methods of the non-professionals.

Of course, there are also gaps in non-professional approaches, notably the evident scope for exploitation, abuse and driving down quality standards in some sectors. Both professionals and non-professionals can learn from the other approach.

This will be important as the new communities become established and long-running, with huge databases of past resources and a complex history to master, making participation more intimidating for new members ("newbies"). Many questions merit further study in this area. Will the communities continue to attract volunteers in sufficient numbers and be able to continue to provide supportive mentoring and leadership? Do nonprofessional codes support the oft-mooted idea of a shared 'model code' or meta-code of ethics? Might volunteering lead to higher motivation and, hence, higher quality levels, at least in some contexts? On what topics do non-professionals seek ethical support and guidance? Are these concerns reflected or addressed in professional codes; and if not, would professionals 
appreciate such guidance too? How are professional translators who act as volunteers in community translation projects placed in terms of ethics: do they import their professional ethics to these contexts or bend to the community's approach?

During the weeks following the Haiti disaster, many hundreds of translators - professionals and non-professionals-volunteered to translate and relay messages to help the rescue effort, often working long hours in difficult conditions on harrowing material. Chat rooms and discussion boards functioned as their "community", and it seems "it was the sense of community that kept many going', knowing that they were part of a larger ongoing effort (Munro, 2010, n.p.). A final ethical concern of relevance to the translation profession has been its traditional isolation, with freelance translators working alone, often many miles from their nearest colleague, albeit that this has been mitigated somewhat recently through increased online networking and support, e.g., through Proz.com or LinkedIn groups. The non-professional online translation community, with its openness, shared values and supportive colleagues, might offer an inspiring and positively ethical model here too.

\section{Appendix 1. Professional codes of translation ethics consulted}

American Translators' Association (ATA). Code of Professional Conduct and Business Practices. Retrieved from http://www.atanet.org/aboutus/ code_of_professional_conduct.php

Association of Translation Companies (ATC). Professional Conduct. Retrieved from http://www.atc.org.uk/code_conduct_atc.html; Ethics. Retrieved from http://www.atc.org.uk/ethics_atc.html

Association suisse des traducteurs, terminologues et interprètes (ASTTI). Code de déontologie. Retrieved from http://www.fit-europe.org/vault/ deontologie-astti.html

Australian Institute of Interpreters and Translators Incorporated (AUSIT). Code of ethics. Retrieved from http://server.dream-fusion.net/ausit2/pics/ ethics.pdf

Belgian Chamber of Translators, Interpreters and Philologists (CBTIPBKVTF). Code de déontologie. Retrieved from http://www.translators.be/ index.php?option $=$ com_content\&task $=$ view\&id $=85 \&$ Itemid $=108 \&$ lang $=\mathrm{fr}$

Chartered Institute of Linguists (UK) Professional Code of Conduct. Retrieved from http://www.iol.org.uk/Charter/CLS/CodeofProfConduct Council17Nov07.pdf 
Danish Association of State-Authorised Translators and Interpreters. Code of Ethics. Retrieved from http://www.fit-europe.org/vault/deont/dk-autheth.html

Indian Translators' Association Code of Conduct. Retrieved from http:// www.itaindia.org/membership_information.pdf

Institute of Translation and Interpreting (UK) Code of Professional Conduct (two separate codes, one for individual members and one for corporate members). Retrieved from links to publications at http://www.iti.org.uk/indexMain.html

Irish Translators' and Interpreters' Association (ITIA).Code of Practice and Professional Ethics. Retrieved from http://www.fit-europe.org/vault/ ITIA_code_ethics.pdf

Israel Translators' Association (ITA). Code of Professional Conduct and Business Practices. Retrieved from http://www.fit-europe.org/vault/ conduct-ita.pdf

Japan Association of Translators Working with Translators (combination of advice for clients and definition of good translation practice, including issues of ethics and professional conduct). Retrieved from http:// jat.org/past/working-with-translators/

Jednota tlumočníkůa překladatelů (Czech Republic). Ethical Code. Retrieved from http:// www.fit-europe.org/vault/ethics-jtp.html

LinguaJuris, Belgium, Code de déontologie des traducteurs, des interprètes et des traducteurs-interprètes jurés. Retrieved from www.linguajuris.org/ data/Codede_Forum_linguaJuris.doc

National Association of Judiciary Interpreters and Translators (USA). Retrieved from http://www.najit.org/publications/Transcript\%20Translation .pdf

Nederlands Genootschap van Tolken en Vertalers (NGTV), Netherlands, Code of Honour. Retrieved from http://www.fit-europe.org/vault/Erecodengtv.html

New Zealand Society of Translators and Interpreters (NZSTI) Code of ethics. Retrieved from http://www.nzsti.org/assets/uploads/ files/codeofethics. pdf 
ProZ.com (largest group of freelance translators, with over 300,000 registered in 2011; their two relevant codes were therefore included). Professional guidelines. Retrieved from http://www.proz.com/professionalguidelines/ Guiding principles. Retrieved from http://www.proz.com/ ?sp $=$ info/cornerstones

Sindicato Nacional dos Tradutores (SINTRA), Brazil. Translators' Code of Ethics - SINTRA Bylaws. Retrieved from http://braziliantranslated.com/ sintrape.pdf

South African guidelines. Retrieved from http://translators.org.za/sati_cms/ downloads/dynamic/sati_ethics_individual_english.pdf

Swedish Association of Professional Translators. Code of Professional Conduct. Retrieved from http://www.fit-europe.org/vault/deont/SFOProfPractice-en.pdf

Syndicat national des traducteurs professionnels (SFT), France. Code de déontologie. Retrieved from http://sft.fr/code-de-deontologie-destraducteurs-et-interpretes.html

UNESCO Nairobi. Recommendation (1976) and Translators' Charter (1994). Retrieved from http://www.fit-ift.org/download/referencebil.pdf

Vereniging Zelfstandige Vertalers (VZV), Netherlands. Code of Ethics. Retrieved from http://www.vZv.info/index.php?section=2\&page $=198$

\section{Appendix 2. Online non-professional 'codes' of translation ethics consulted}

Adobe community translation http://tv.adobe.com/translations/guidelines http://tv.adobe.com/translations/terms

Apache project

http://www.apache.org/foundation/bylaws.html

D-Addicts fansubbing forum http://www.d-addicts.com/forum/viewforum 43.htm $\mathrm{http} / / /$ www.d-addicts.com/forum/viewtopic_38531.htm

Doctors Without Borders/Médecins sans frontières Charter http://www.doctorswithoutborders.org/aboutus/charter.cfm 
Facebook translation Terms of Service

http://www.facebook.com/translations/index.php?app=1\&aloc=en_GB\&hel $\mathrm{p}$

Global Voices Project Lingua

$\mathrm{http} / / /$ globalvoicesonline.org/lingua/

http://globalvoicesonline.org/about/gv-manifesto/

Joomla! Open Source project

General Volunteer Code of Conduct: http://www.joomla.org/aboutjoomla/the-project/code-of-conduct.html

Translation and Localization Policy:

http://community.joomla.org/translations/translation-policy.html

OpenOffice

Terms of use: http://openoffice.org/terms_of_use

Community forum: http://user.services.openoffice.org/en/forum/

Second Life community and translation guidelines

http://wiki.secondlife.com/wiki/Linden_Lab_Official:Discussion_guideline $\mathrm{s}$

http://wiki.secondlife.com/wiki/Community_Translation_Project

Sun Open Community Translation Interface

https://translate.sun.com/opencti/resources/tou.html

TranslateWiki.net

http://ranslatewiki.net/wiki/Support

http://en.wikipedia.org/wiki/Wikipedia:Text_of_Creative_Commons_Attrib ution-ShareAlike_3.0_Unported_License

Translation Cloud Terms and Conditions https://docs.google.com/document/pub?id=1S8DGTPb-

WOXJIJ144ct3dbbL2u871HIXH6wzyuvx6dw

Translations for Progress

http://www.translationsforprogress.org/ngoguide.php

http://www.translationsforprogress.org/translatorsguide.php

Twitter Translation Environment - not translation-specific but users are bound by the Twitter Rules addressing some relevant issues http://support.twitter.com/articles/18311-the-twitter-rules

Ubuntu

Code of Conduct: http://www.ubuntu.com/community/conduct 
Broader definition of 'values':

http://www.ubuntu.com/community/ubuntuvalues

Wikipedia. Various codes of relevance here, including the general: http://wikimediafoundation.org/wiki/Terms_of_Use

And two more specific to translation:

http://meta.wikimedia.org/wiki/Translation

http://meta.wikimedia.org/wiki/Wikimedia_principles

\section{References}

Banerjee, D., Cronan, T. P., \& Jones, T. W. (1998). Modeling IT ethics: A study in situational ethics. MIS Quarterly, 22(1), 31-60.

Brooks, L. J. (1989). Corporate codes of ethics. Journal of Business Ethics, 8(2/3), 117129.

Chesterman, A. (2009). Ethics of translation. In M. Baker (Ed.), Translation Studies (pp. 34-43). Abingdon: Routledge.

Davis, M. (2003). What can we learn by looking for the first code of professional ethics? Theoretical Medicine and Bioethics, 24(5), 433-454.

DePalma, D., \& Kelly, N. (2008). Translation of, for, and by the people. Lowell, MA: Common Sense Advisory.

Désilets, A. (2007). Translation wikified: How will massive online collaboration impact the world of translation? Proceedings of translating and the computer (29). London: Aslib.

Frankel, M. S. (1989). Professional codes: Why, how and with what impact? Journal of Business Ethics, 8(2/3), 109-115.

Floridi, L. (1999). Information ethics: On the philosophical foundation of computer ethics. Ethics and Information Technology, 1, 37-56

Garcia, I. (2009). Beyond Translation Memory: computers and the professional translator. The Journal of Specialised Translation, 12, 199-214.

Gaumnitz, B. R., \& Lere, J. C. (2002). Contents of codes of ethics of professional business organizations in the United States. Journal of Business Ethics, 35(1), $35-49$.

Gneezy, U., \& Rustichini, A. (2000). Pay enough or don't pay at all. The Quarterly Journal of Economics, 115(3), 791-810.

Goodwin, P. (2010). Ethical problems in translation. Why we might need Steiner after all. The Translator, 16(1), 19-42.

Gouadec, D. (2009). Profession traducteur. Paris: La Maison du Dictionnaire.

Higgs-Kleyn, N., \& Kapelianis, D. (1999). The role of professional codes in regulating ethical conduct. Journal of Business Ethics, 19(4), 363-374.

Howe, J. (2008). Crowdsourcing. How the power of the crowd is driving the future of business. New York: Random House.

Koehler, W. C., \& Pemberton, J. M. (2000). A search for core values. Towards a model code of ethics for information professionals. Journal of Information Ethics, 9(1), 26-54.

Künzli, A. (2007). The ethical dimension of translation revision. An empirical study. The Journal of Specialised Translation, 8, 42-56.

Lewis, W. D. (2010). Haitian Creole: How to build and ship an MT engine from scratch in 4 days, 17 hours, \& 30 minutes. In F. Yvon \& V. Hansen (Eds.), EAMT 2010. 
Proceedings of the $14^{\text {th }}$ Annual Conference of the European Association for Machine Translation. Saint-Raphaël, France.

Loch, K. D., \& Conger, S. (1996). Evaluating ethical decision making and computer use. Communications of the ACM, 39(7), 74-83.

Marshall, K. P. (1999). Has technology introduced new ethical problems? Journal of Business Ethics, 19(1), 81-90.

McDonough Dolmaya, J. (2011). Moral ambiguity: Some shortcomings of professional codes of ethics for translators. The Journal of Specialised Translation, 15, 2849.

Munro, R. (2010). Crowdsourced translation for emergency response in Haiti: the global collaboration of local knowledge. AMTA Workshop on Collaborative Crowdsourcing for Translation. Denver, Colorado, USA.

Savan, B. (1989). Beyond professional ethics: Issues and agendas. Journal of Business Ethics, 8(2/3), 179-185.

Souphavanh, A. and Karoonboonyanan, T. (2005) Free / Open Source Software: Localization. UNDP-APDIP. Retrieved from http://www.apdip.net/publications/fosseprimers/foss-110n.pdf

Wagner, E. (2005). Does ITI's Code of Conduct need a makeover? ITI Bulletin, (MayJune), 20-23.

Warner, D. E., \& Raiter, M. (2005). Social context in Massively-Multiplayer Online Games (MMOGs): Ethical questions in shared space. International Review of Information Ethics, 4(12), 46-52.

Wooten, A. (2011). Can companies obtain free professional services through crowdsourcing? Deserets news. Retrieved from http://www.deseretnews.com/.

1 See Appendix 1 for a representative sample of codes in English and French. The terms 'code of conduct/ethics' are not defined here for reasons of space and because they are used interchangeably in professional contexts. Among others, Marshall (1999: 82) and Wikipedia (http://meta.wikimedia.org/wiki/Simple_View_of_Ethics_and_Morals) give relevant outlines.

2 DePalma and Kelly (2008) and TAUS, among others, favour this term; other terms refer to the same phenomenon. Garcia (2009: 210) suggests 'hive' translation. I use the range here but prefer 'non-professional' translation, as the latter avoids potential confusion with community translation/interpreting as previously widely understood, i.e. translation for minority languages or in public service contexts. I include here initiatives where low payment is available to participants, e.g., TranslationCloud.net.

3 These are not listed in the Appendix as they were given to the author for research purposes on the condition of confidentiality.

4 In this, McDonough Dolmaya's approach is typical, in that it considers only those codes specific to the translation industry. Other surveys of ethical code content also focus on one profession alone, such as IT (Floridi, 1999) or business (Gaumnitz and Lere, 2002). 